Research Paper

\title{
Risk Assessment and Hydrodissection Technique for Radiofrequency Ablation of Thyroid Benign Nodules
}

\author{
Tang Xiaoyin\#, Li Ping\#, Cui Dan, Ding Min, Chi Jiachang, Wang Tao, Shi Yaoping, Wang Zhi, Zhai Bo ${ }^{\bowtie}$ \\ Department of Tumor Interventional Oncology, Renji Hospital, School of Medicine, Shanghai Jiaotong University,160\# Pujian Road, Shanghai, 200127, China \\ \# These authors contributed equally to this study \\ $\triangle$ Corresponding author: Bo Zhai (PhD, MD), Department of Interventional Oncology, Renji Hospital, School of Medicine, Shanghai Jiaotong University, 160\# \\ Pujian Road, Shanghai, 200127, China. Telephone: 0086-21-68383134; Fax: 0086-21-68383134; Email: zhaibo@renji.com \\ (C) Ivyspring International Publisher. This is an open access article distributed under the terms of the Creative Commons Attribution (CC BY-NC) license \\ (https://creativecommons.org/licenses/by-nc/4.0/). See http://ivyspring.com/terms for full terms and conditions.
}

Received: 2018.03.14; Accepted: 2018.07.02; Published: 2018.08.06

\begin{abstract}
Purpose: This retrospective study aimed to explore the importance of risk assessment and hydrodissection pre-treatment for radiofrequency ablation of thyroid nodules and initially establish the concept of thyroid nodule risk assessment and the corresponding ablation norms.

Method: Based on the specific location of thyroid nodules, risk assessment and the corresponding preventive measures for thyroid ablation were established. During the period of 2015.10-2017.5, a total of 382 patients were enrolled to compare the safety and efficacy of the ablation for patients with or without risk assessment and the corresponding preventive measures. Statistical analysis encompassed Independent $T$ test for continuous variables and Fisher's exact test/Chi-square test for categorical variables.

Result: Of all 382 patients, 188 patients underwent ablation with risk assessment and the corresponding preventive measures before ablation and 194 without, respectively. The patient characteristics, risk grading, ablation time, thyroid function after ablation and the complete ablation rate showed no statistical differences exsisted between two groups $(P>0.05)$. The complication in very high risk nodules was avoided in the group of patients with risk assessment and preventive measures before ablation.

Conclusion: It is a very safe and effective way to carry out radiofrequency ablation after pre-treatment of thyroid nodules by hydrodissection technique according to risk assessment. It will provide clinicians with greater help in the ablation treatment of thyroid nodules, and improve the safety of the thyroid ablation.
\end{abstract}

Key words: Thyroid Nodule; Neoplasm Grading; Ablation Techniques; Evaluation Studies; Comparative Study.

\section{Introduction}

Thyroid nodules accompanied with partially compressive symptoms or malignant trendency need to be treated $[1,2]$. Currently, traditional treatments for thyroid nodules are medication and surgery. The effect of thyroxin treatment still remains controversial. The relapse rate was significantly high when the drug was discontinued. Also the long term use of thyroxin could lead to a series of side effects. Relatively, the effect of surgical treatment was more obvious; however, it was not accepted by some patients due to its relatively high incidence of complications, including long incision, more bleeding, permanent scar in the neck, reduced thyroid function and permanent injury of the superior or recurrent laryngeal nerve.

Radiofrequency ablation (RFA) has been widely used in the treatment of thyroid nodules, and it has been confirmed to be effective and safe $[3,4]$. However, due to the small size, and complex adjacent structures of the thyroid gland, there is still a certain rate of complications occurred during ablation. The recurrent laryngeal nerve injury caused by heat injury 
was occurred with the incidence of $1.02 \%-2.4 \%$ [5-7]. In addition to the recurrent laryngeal nerve, the anterior cervical muscles, trachea, esophagus, common carotid artery, internal jugular vein, parathyroid glands, cervical sympathetic trunk and vagus nerve are also closed to the thyroid $[8,9]$. These structures are likely to be damaged during thermal ablation, and should be protected before thermal ablation. Currently, RFA of thyroid nodules is mostly performed under ultrasound guidance [10]. Although current ultrasound reports could guide the surgical treatment of thyroid nodules, it is impossible to accurately describe the risk of thyroid nodules at different sites during ablation.

From November 2014, ultrasound-guided RFA of thyroid nodules was performed in our department. In clinical practice, we found that the difficulty and risk of the ablation were significantly different because of the location and the adjacent structures of the nodules, even if they owned the same size. In the thermal ablation of thyroid nodules, if ignoring these differences, the risk of the ablation and the postoperative complication occurrence rate might be increased. Therefore, summarizing our clinical experience of thyroid nodules, we firstly established a risk assessment method for ablation based on the location and adjacent structures of thyroid nodules to clarify the risk degree of each nodule. According to the risk assessment, hydrodissection technique, which was focused on separating the thyroid nodules from the surrounding important structures, was performed before ablation to ensure the safety of ablation treatment and reduce the incidence of complications. In this study, the risk assessment method and the hydrodissection technique for ablation of thyroid nodules were systematically described. Also, the effects of these techniques were evaluated in the treatment of benign thyroid nodules in our center.

\section{Materials and Methods}

\section{Patients}

From November 2014, ultrasound-guided percutaneous radiofrequency ablation was carried out in our hospital after the approval of the ethics committee of our hospital. All patients gave written informed consent before treatment. Patients underwent ablation had to meet all of the following criteria. Inclusion criteria: (1) Patients who were clearly diagnosed with benign thyroid nodules by ultrasound-guided thyroid fine needle aspiration cytology biopsy according to the guideline of American Thyroid Association (ATA); (2) Patients had obvious compressive symptoms because of the large thyroid nodules $(\geq 2 \mathrm{~cm})$, or patients had nodules classified as TI-RADS $4 \mathrm{a}$ or above, worried about malignancy and wanted to be treated. (3) Patients who voluntarily received radiofrequency ablation; (4) Patients with normal thyroid function or those whose thyroid function has been adjusted to the normal range by endocrine treatment; (5) Patients with normal coagulation function during preoperative blood tests; (6) Patients with a normal chest radiograph and electrocardiogram (ECG) recording; Exclusion criteria: (1) Patients who were clearly diagnosed with malignant thyroid tumors by ultrasound-guided thyroid fine needle aspiration cytology biopsy; (2) Female patients in pregnancy or lactation; (3) Patients accompanied with severe systemic disease, such as severe coagulation disorders, myocardial infarction, stroke, cancer, connective tissue disease (scleroderma or systemic lupus erythematosus), systemic infection and uncontrolled diabetes; (4) Patients accompanied with severe physical, neurological and psychiatric disorders.

Before ablation, all patients underwent contrast-enhanced ultrasonography and ultrasonography to observe the nodules. And thyroid function tests were examined pre- and first day after RFA. During ablation, for patients with multiple nodules, all nodules including $\geq 2 \mathrm{~cm}$ and $<2 \mathrm{~cm}$, were treated.

\section{Risk assessment and preventive measures}

In clinical practice, based on the position of thyroid nodules, we established a risk assessment method for the ablation of benign thyroid nodules, and explored a corresponding preventive measure of "hydrodissection technique" to improve the safety of the ablation. And from August 2016, the risk assessment method and the preventive measure of "hydrodissection technique" systematically started to be used in our center.

\section{Risk assessment method for ablation}

Due to the small volume and complex adjacent structure of thyroid, it still has a certain incidence of complications for the ablation. The adjacent structures, such as recurrent laryngeal nerve, anterior cervical muscles, trachea, esophagus, common carotid artery, internal jugular vein, parathyroid glands, cervical sympathetic trunk and vagus nerve, might be thermally damaged during thermal ablation. Using ultrasound, we divided the risk of ablation into four grades to guide the ablation process of thyroid nodules based on the location and distance from adjacent structures of the nodule. The evaluated criterion (Table 1) was based on consideration of the following concepts:

Grade 0, low risk: Nodules located in the thyroid gland parenchyma, and were far away $(\geq 2 \mathrm{~mm})$ from all important structures in the neck (Figure 1(A)). 
Conventional radiofrequency ablation was needed during the treatment process with completely ablation as the goal.

Table 1. The risk assessment system for the ablation of benign thyroid nodules

Grade Location of nodules

Grade 0, low risk Nodules located in the thyroid parenchyma, and the distance between nodule edge and adjacent important structures was $\geq 2 \mathrm{~mm}$.

Grade 1, median risk The distance between nodule edge and carotid sheath, anterior cervical muscles or cervical posterior muscles was less than $2 \mathrm{~mm}$.

Grade 2, high risk The distance between nodule edge and trachea, esophagus, or recurrent laryngeal nerve was less than $2 \mathrm{~mm}$.

Grade 3,Very high Both Grade 1 and Grade 2 were existed. risk

A
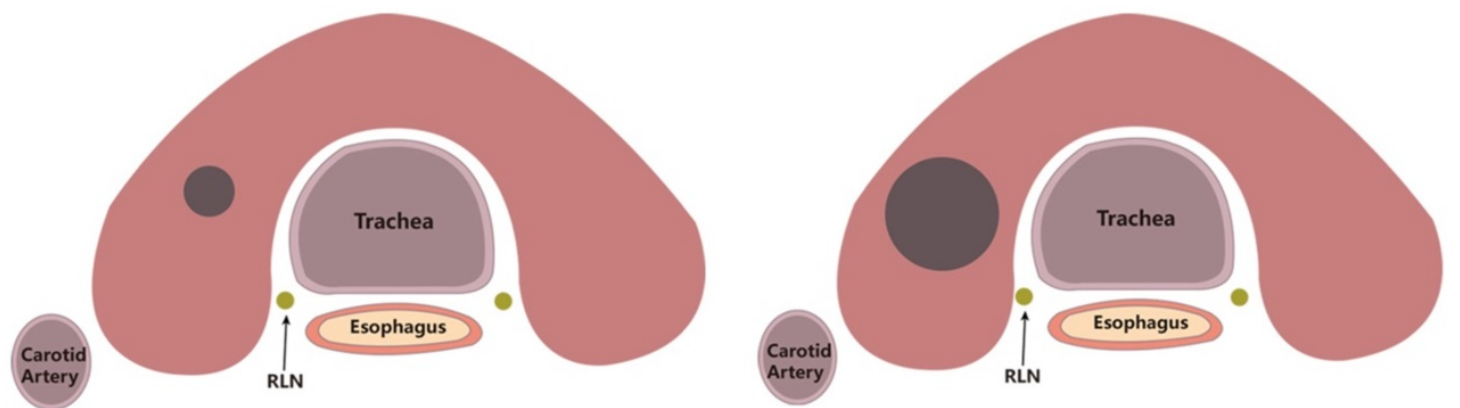

B
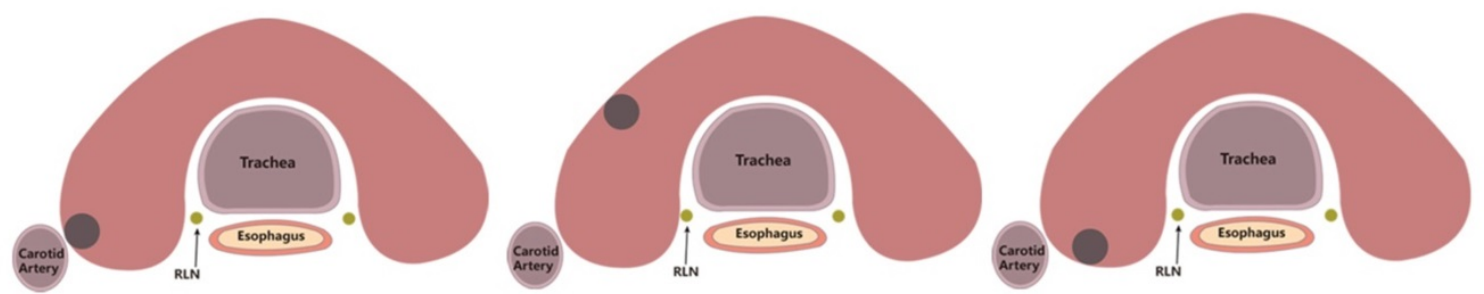

C
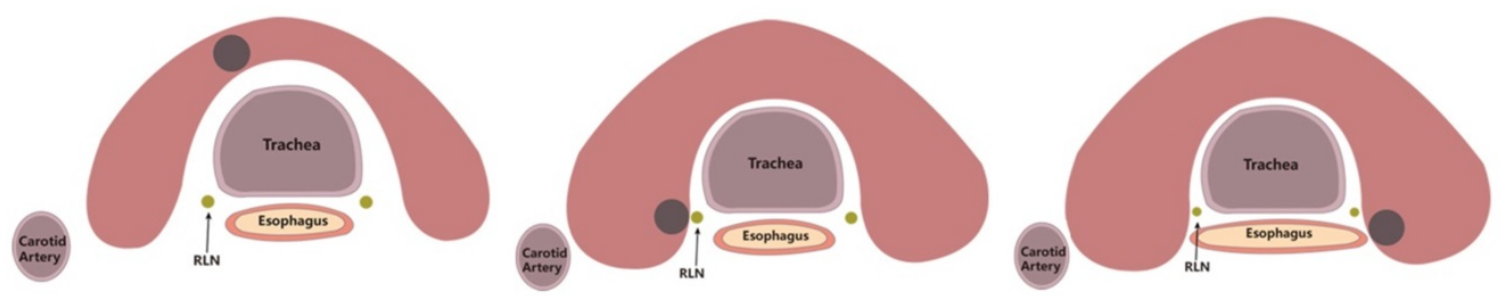

D
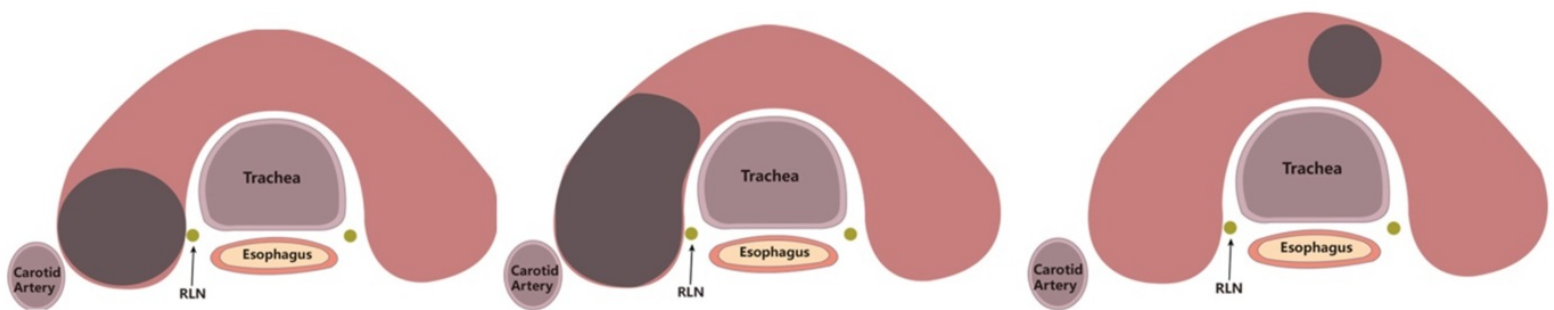

Figure 1. Location of nodules in different risk grade. A, Grade 0, Low risk location. B, Grade 1, Median risk location. C, Grade 2, High risk location. D, Grade 3, Very high risk location.
Grade 1, median risk: These nodules located far away from recurrent laryngeal nerve, trachea, esophagus and so on, however the distance between the margin of the nodules and carotid sheath, anterior cervical muscles or cervical posterior muscles was less than $2 \mathrm{~mm}$ (Figure 1(B)). During ablation, the major risk was the damage of the anterior cervical muscles, posterior cervical muscles, skin, blood vessels or nerves on the surface of thyroid. The complications after ablation included long-term discomfort in the neck, unsightly appearance, or other corresponding symptoms of blood vessel and nerve injury. The impact of these complications was relatively mild, and this type of nodules was classified as Grade 1, defined as a median risk nodule. 
Grade 2, high risk: The distance between the nodules and the trachea, esophagus or recurrent laryngeal nerve was less than $2 \mathrm{~mm}$ (Figure $1(\mathrm{C})$ ). In the ablation process, the damage of trachea, esophagus or recurrent laryngeal nerve caused by thermal energy, could not cure by itself and require surgical treatment. The damage of these organs was serious, especially for the injury of recurrent laryngeal nerve. These nodules were classified as Grade 2, defined as high risk nodules.

Grade 3, very high risk: This type of nodules located within $2 \mathrm{~mm}$ around the recurrent laryngeal nerve, trachea, or esophagus $(<2 \mathrm{~mm})$, while the distance to carotid sheath, anterior cervical muscles or cervical posterior muscles was also less than $2 \mathrm{~mm}$ (Figure 1(D)). Due to the difficulty and high risk of
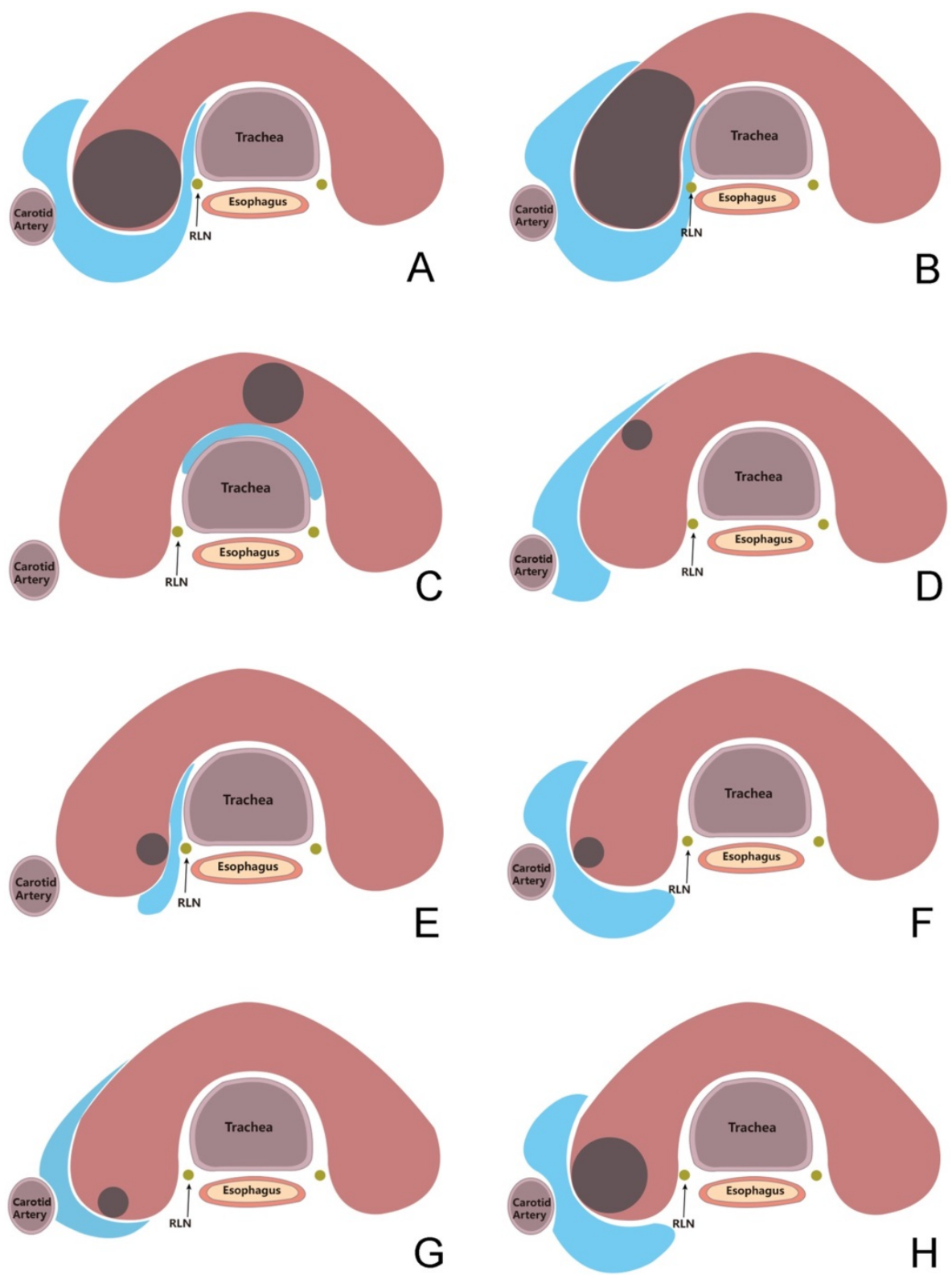

ablation, these nodules were classified as Grade 3, defined as very high risk nodules.

\section{"Hydrodissection technique", a pretreatment to ensure the safety of ablation}

To ensure the safety of ablation, we developed a pretreatment of "hydrodissection technique". For nodules of Grade 1-3, the "hydrodissection technique" was used before the ablation. Using sterile syringe, sterile water was injected between the thyroid nodules and surrounding tissues, until the nodules and surrounding tissues were completely separated. Then the ablation was performed and during the ablation sterile water was continuously injected to ensure the completely separated status of the nodules from surrounding tissues $(>2 \mathrm{~mm}$ between nodules and surrounding tissues) (Figure 2).

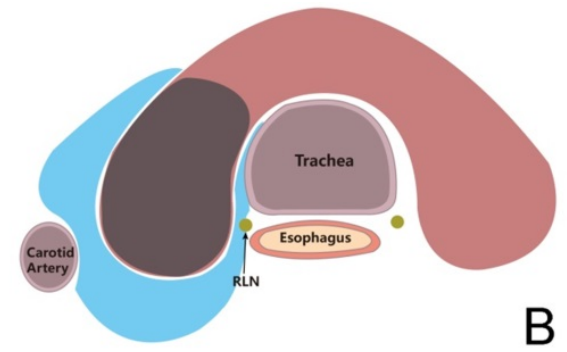

B

Figure 2. "Hydrodissection technique" for nodules in risk areas. A-H, the range and effect of the hydrodissection for nodules in different location. 
For patients with nodules of Grade 1-3, general anesthesia was used to ensure the performance of the "hydrodissection technique" and the accurate vital signs were monitored during ablation. Considering the opinion of patients, general or local anesthesia was used for other patients with nodules of Grade 0.

\section{Radiofrequency ablation therapy}

Medsphere RF Generator S-500 (Medsphere, Shanghai, China) was used for RFA treatment. Radiofrequency ablation was performed in the operating room. Tracheal intubation was used for general anesthesia and local anesthesia was performed for some patients. Local anesthesia was performed for patients meeting the following conditions: (1) Fewer than three nodules; (2) The largest nodule measuring less than $2 \mathrm{~cm}$ in diameter; (3) The expected entire operation time was less than 30 min; (4) No history of hypertension; (5) Patients with good compliance. Otherwise, general anesthesia was selected. After anesthesia, a shoulder pillow and a neck pillow were put under the patient's shoulder and neck to make patients remain neck extensional position. Patients were routinely disinfected before paving sterile sheet. Methylprednisolone $(40 \mathrm{mg})$ was administrated before ablation to prevent glandular dilatation or thyroid crisis [11]. Radiofrequency ablation power was adjusted to $20-40 \mathrm{~W}$, using the impedance mode. Based on the diameter of nodules parallel to the ultrasonic probe, the different ablation electrode was selected, electrode with $0.5 \mathrm{~cm}$ active tip was selected for nodules $<1 \mathrm{~cm}$, while electrode with $1 \mathrm{~cm}$ active tip was selected for nodules $>1 \mathrm{~cm}$. The vicinity of thyroid gap near the neck front center line was prior selected as the insertion position of ablation needle and the radiofrequency electrode was punctured into the bottom of the tumor through thyroid nodules under ultrasound guidance. After radiofrequency ablation instrument started, vaporization was observed around the electrode until the tumor was completely covered by transient hyperechoic zone. For large nodules $(\geq 2 \mathrm{~cm})$, if effective ablation could not be achieved by the single site ablation, then multi-plane puncture and multi-level ablation method were used. By adjusting the direction of the electrode and ablation plane, multiple ablations were performed until the tumor in the three-dimensional space was completely covered by transient hyperechoic zone. Ultrasonography was used to evaluate the ablation of thyroid nodules in real time during ablation. If there were some areas of reinforcement within the nodules, timely supplemental ablation could be carried out to avoid nodule residue to the greatest extent. After ablation, repeated ultrasound angiography was performed to observe the thyroid nodule contrast agent perfusion.

\section{Postoperative review}

One month after radiofrequency ablation, all patients underwent contrast-enhanced ultrasonography and ultrasonography to observe whether their thyroid nodules were completely ablated, so as to evaluate the efficacy of radiofrequency ablation. Completely ablation was defined as no contrast agent perfusion after injection of ultrasound contrast agent (SonoVue) in postoperative thyroid nodules. However, if there was local perfusion in the lesion area, it was indicated that thyroid nodules were not completely ablated. In addition, thyroid function changes and complications were also recorded to assess the safety of radiofrequency ablation.

\section{Statistical analysis}

Continuous parameters were expressed as median and range, while categorical variables were expressed as number and percentage. Independent $\mathrm{T}$ test for continuous variables and Fisher's exact test/Chi-square test for categorical variables were employed to perform statistical analysis betweengroup comparisons. And statistical significance was set at $\mathrm{P}<0.05$. SPSS version 22.0 (IBM Co., Armonk, $\mathrm{NY}$, USA) was performed for all statistical analyses.

\section{Results}

From August 2016, we systematically used the risk assessment method and "hydrodissection technique" in the clinical practice. Between August 2016 and May 2017, 188 patients with 626 nodules underwent ablation in our center. Based on the risk assessment methods, the nodules of every patient were evaluated and the "hydrodissection technique" was performed on nodules of Grade 1-3 before ablation. Also we retrospectively reviewed and evaluated 756 nodules of 194 patients which were ablated in the period between October 2015 and July 2016. The safety and efficacy of ablation between two periods were compared.

\section{Clinical characters and risk grading}

A total of 382 patients studied in this comparison, including 194 patients underwent ablation without risk assessment and pretreatment between October 2015 and July 2016, while 188 patients were evaluated by the risk of the nodules and pretreated by the "hydrodissection technique" before ablation between August 2016 and May 2017. The detailed characters were shown in Table 2. The age, gender, nodules' number, size of the nodules, and even the thyroid function were similar between two periods $(\mathrm{P}>0.05)$. 
Table 2. Patient Characteristics

\begin{tabular}{|c|c|c|c|}
\hline Characteristics & 2015.10-2016.7 & 2016.8-2017.5 & Pvalue* \\
\hline No. of patients & 194 & 188 & / \\
\hline No. of nodules & 756 & 626 & / \\
\hline No. of nodules treated per patient & & & 0.072 \\
\hline Median (Range) & $3(1-17)$ & $3(1-12)$ & \\
\hline 1 & $48(24.7 \%)$ & $38(20.2 \%)$ & \\
\hline 2 & $28(14.4 \%)$ & $44(23.4 \%)$ & \\
\hline$>2$ & $118(60.8 \%)$ & $106(56.4 \%)$ & \\
\hline Size of nodules, $\mathrm{mm}$ & & & 0.576 \\
\hline Median (Range) & $6.7(2-67)$ & $6.8(1-60)$ & \\
\hline$<=20 \mathrm{~mm}$ & $682(90.2 \%)$ & $559(89.3 \%)$ & \\
\hline$>20 \mathrm{~mm}$ & $74(9.8 \%)$ & $67(10.7 \%)$ & \\
\hline Age, years & & & 0.64 \\
\hline Median (Range) & $50(17-83)$ & $48(25-79)$ & \\
\hline Gender & & & 0.30 \\
\hline Male & $37(19.1 \%)$ & $44(23.4 \%)$ & \\
\hline Female & $157(80.9 \%)$ & $144(76.6 \%)$ & \\
\hline \multicolumn{4}{|l|}{$\begin{array}{l}\text { Thyroid function index, } \\
\text { Median(Range) }\end{array}$} \\
\hline FT3 & $4.99(2.95-7.96)$ & $4.895(3.28-8.45)$ & 0.84 \\
\hline FT4 & $15.965(6.75-120)$ & $15.64(0.3-22.31)$ & 0.08 \\
\hline TGAb & $0.12(0.12-2000)$ & $0.12(0.1-2000)$ & 0.33 \\
\hline TPOAb & $11.415(1.78-660.9)$ & $15.485(0.1-600)$ & 0.90 \\
\hline TRAb & $0.3(0.3-519.3)$ & $0.3(0.03-7.95)$ & 0.33 \\
\hline TSH & $1.305(0.01-14.56)$ & $1.735(0.01-9.91)$ & 0.08 \\
\hline
\end{tabular}

* P value was calculated using the Independent $T$ test for continuous variables and Chi-square test for categorical variables.

According to the risk assessment, the risk of the nodules and patients in two periods were evaluated. As showed in Table 3, very high risk nodules accounted for the largest nodules both in the two periods (2015.10-2016.7: 335/44.3\% VS 2016.8-2017.5: 295/47.1\%). Meanwhile, the majority of the patients between two periods were located in the very high risk grade (2015.10-2016.7: $155 / 80.0 \%$ VS 2016.8-2017.5: 152/80.8\%). There was no significantly differences existed in the risk of nodules and patients between the two periods.

Table 3. The risk grading of patients between two periods

\begin{tabular}{|c|c|c|c|c|c|}
\hline \multirow[t]{2}{*}{ Risk Grading } & \multicolumn{2}{|c|}{ 2015.10-2016.7 } & \multicolumn{2}{|c|}{ 2016.8-2017.5 } & \multirow[t]{2}{*}{ Pvalue* } \\
\hline & $\begin{array}{l}\text { Nodules } \\
\text { no. }\end{array}$ & $\begin{array}{l}\text { Patients } \\
\text { no**. }\end{array}$ & $\begin{array}{l}\text { Nodules } \\
\text { no. }\end{array}$ & $\begin{array}{l}\text { Patients } \\
\text { no**. }\end{array}$ & \\
\hline 0, Low risk & $64(8.5 \%)$ & $3(1.5 \%)$ & $45(7.2 \%)$ & $2(1.1 \%)$ & Nodules \\
\hline 1, Medium risk & $278(36.8 \%)$ & $27(13.9 \%)$ & $237(37.9 \%)$ & $26(13.8 \%)$ & 0.267 \\
\hline 2, High risk & $79(10.4 \%)$ & $9(4.6 \%)$ & $49(7.8 \%)$ & $8(4.3 \%)$ & Patients: \\
\hline $\begin{array}{l}3 \text {, Very high } \\
\text { risk }\end{array}$ & $335(44.3 \%)$ & $155(80.0 \%)$ & $295(47.1 \%)$ & $152(80.8 \%)$ & 0.975 \\
\hline
\end{tabular}

For each patient in the period of 2016.8- 2017.5, risk assessment was performed for all nodules and "hydrodissection technique" was used for nodules of Grade 1-3 before the ablation to ensure the safety. An example of a patient with a nodule of Grade 3 was shown in Figure 3.

\section{Postoperative complications and clinical outcomes}

Both in two periods, ultrasound-guided percutaneous thyroid nodule radiofrequency ablation was performed successfully. In the period of without risk assessment and pretreatment, three patients $(1.6 \%)$ occurred the damage of recurrent laryngeal nerve, while one patient $(0.5 \%)$ occurred the damage of cervical sympathetic trunk. All four patients were evaluated as very high risk grade. After using the risk assessment and pretreatment, no server complication was found, such as severe bleeding, skin burns and severe thyroid crisis. More importantly, damage of anterior cervical muscle, recurrent laryngeal nerve, trachea, esophagus, common carotid artery, internal jugular vein, parathyroid glands, cervical sympathetic trunk and vagus nerve was also not occurred. The occurrence of the complication was reduced after the using of the risk assessment and the "hydrodissection technique" pretreatment. However, the total ablation time was similarly, and the indexes of the thyroid function were in normal range and no obvious difference existed between two periods $(\mathrm{P}>0.05)$ (Table 4).

Table 4. The complications and clinical outcomes after ablation compared between two periods.

\begin{tabular}{|c|c|c|c|}
\hline & 2015.10-2016.7 & 2016.8-2017.5 & Pvalue* \\
\hline \multicolumn{4}{|c|}{ Complication rate among different risk grading (Patient Number(n), rate(\%) } \\
\hline 0 , Low risk & $0(0 \%)$ & $0(0 \%)$ & / \\
\hline 1, Medium risk & $0(0 \%)$ & $0(0 \%)$ & / \\
\hline 2, High risk & $0(0 \%)$ & $0(0 \%)$ & / \\
\hline 3, Very high risk & $4(2.1 \%)$ & $0(0 \%)$ & 0.123 \\
\hline \multicolumn{4}{|c|}{ Complications (Patient Number(n), rate $(\%)$ ) } \\
\hline Severe bleeding & $0(0 \%)$ & $0(0 \%)$ & / \\
\hline Skin burns & $0(0 \%)$ & $0(0 \%)$ & / \\
\hline $\begin{array}{l}\text { Damage of anterior cervical } \\
\text { muscle }\end{array}$ & $0(0 \%)$ & $0(0 \%)$ & / \\
\hline $\begin{array}{l}\text { Damage of recurrent laryngeal } \\
\text { nerve }\end{array}$ & $3(1.6 \%)$ & $0(0 \%)$ & 0.248 \\
\hline Damage of esophagus & $0(0 \%)$ & $0(0 \%)$ & / \\
\hline $\begin{array}{l}\text { Damage of common carotid } \\
\text { artery }\end{array}$ & $0(0 \%)$ & $0(0 \%)$ & / \\
\hline Damage of internal jugular vein & $0(0 \%)$ & $0(0 \%)$ & / \\
\hline Damage of parathyroid glands & $0(0 \%)$ & $0(0 \%)$ & / \\
\hline $\begin{array}{l}\text { Damage of cervical } \\
\text { sympathetic trunk }\end{array}$ & $1(0.5 \%)$ & $0(0 \%)$ & 1.000 \\
\hline Damage of vagus nerve & $0(0 \%)$ & $0(0 \%)$ & / \\
\hline \multicolumn{4}{|c|}{ Total ablation time for one patient, mean ( $\mathrm{min})$} \\
\hline Total ablation time & 2.47 & 1.53 & 0.06 \\
\hline \multicolumn{4}{|c|}{ Thyroid function one month after ablation, Median(Range) } \\
\hline FT3 & $4.855(3.7-11.99)$ & $4.88(3.64-53.69)$ & 0.08 \\
\hline TGAb & $15.24(8.81-24.31)$ & $14.905(1.55-67.19)$ & 0.35 \\
\hline TPOAb & $0.12(0.12-2000)$ & $0.12(0.12-4000)$ & 0.87 \\
\hline $\mathrm{TRAb}$ & $10.885(5-600)$ & $16.57(5-600)$ & 0.34 \\
\hline TSH & $0.3(0.3-10.96))$ & $0.3(0.3-20.45)$ & 0.77 \\
\hline FT4 & $1.495(0.01-36.52)$ & $1.69(0.01-12.04)$ & 0.66 \\
\hline
\end{tabular}

* P value was calculated using the Independent $\mathrm{T}$ test for continuous variables and Fisher's exact test for categorical variables.

\section{Efficacy of ablation}

Postoperative review results 1 month after radiofrequency ablation showed that, the complete ablation (CA) rate was comparable between two periods (94.84\% VS $94.15 \%, \mathrm{P}=0.765)$. For the mean volume reduction ratio (VRR), no significantly differences occurred between two periods $(P=0.59)$, 

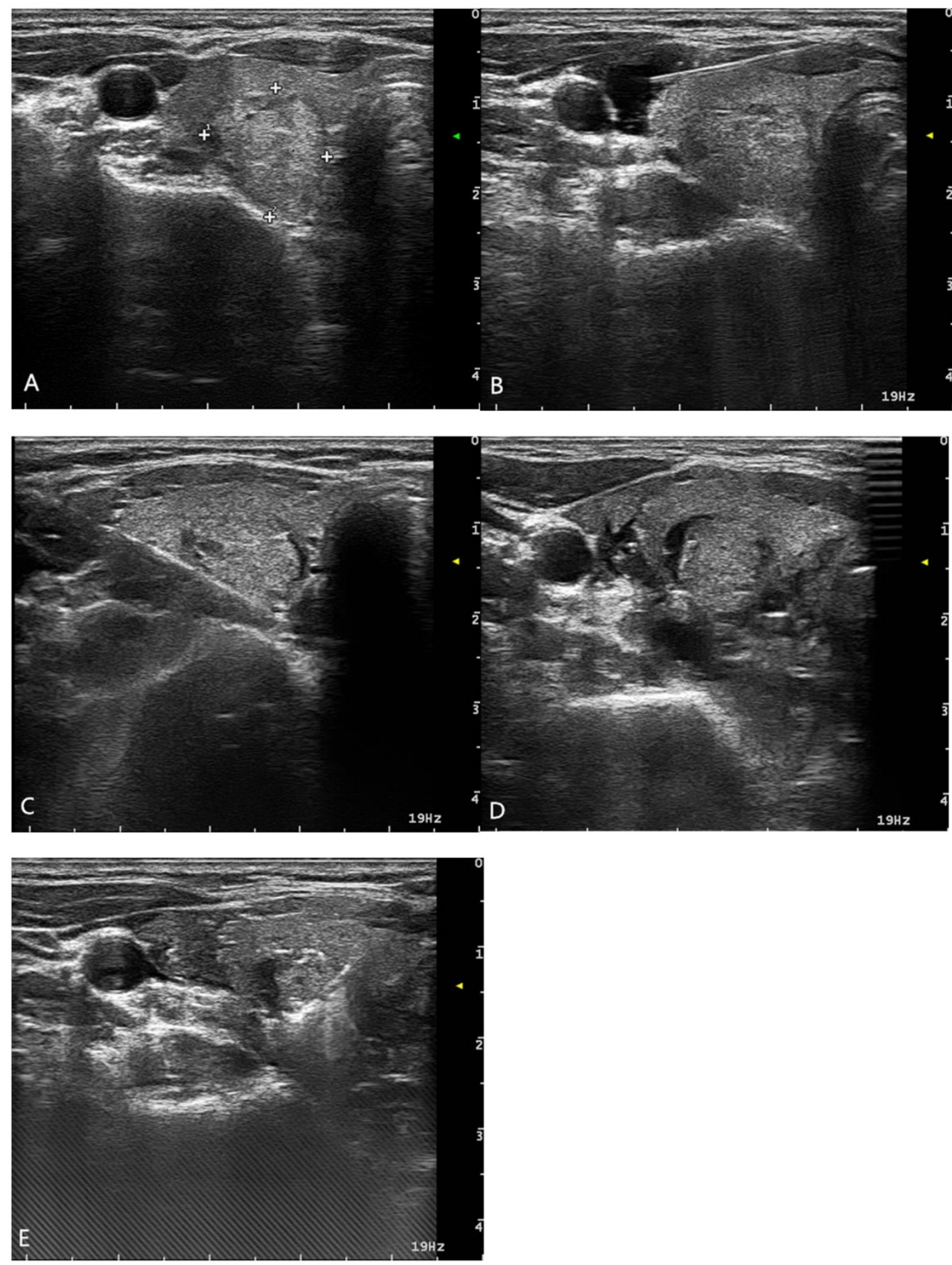

Figure 3. A patient with a nodule of Grade 3. (A) Preoperative US, (B) Sterile water was injected along the carotid sheath, (C) Sterile water was injected into the backside of the thyroid, (D) Sterile water was injected into the space between the trachea and the thyroid gland, (E) Ablation with the Hydrodissection technique

the average of the volume reduction was reached to $23 \%$ and $30 \%$ in two periods.

\section{Discussion}

In this study, we compared the clinical outcomes of ablation patients with benign thyroid nodules before and after the using of the risk assessment and the hydrodissection technique pre-treatment. Both in two periods, we aimed to receive the complete ablation of all nodules, the nodules including $\geq 2 \mathrm{~cm}$ and $<2 \mathrm{~cm}$, were all covered by the ablation range. And the safety of the ablation was improved after the using of the risk assessment and hydrodissection technique. Also, the performance of the hydrodissection technique was simple and the total ablation time was not affected. And the thyroid function was also not affected by the pretreatment.

For a long time, surgery has been the traditional treatment of thyroid benign nodules, which can 
remove the tumor to a better extent. However, postoperative negative impact on thyroid function is very serious. Researchers have found that surgery has a high incidence of omplications, such as recurrent laryngeal nerve injury (incidence rate: 0.2-1.1\%), hypoparathyroidism, hypothyroidism and permanent hypocalcemia (incidence rate: 1\%) [12-19]. A study of 200 patients with partially thyroidectomy showed that up to $71.5 \%$ of patients occurred hyphyroidsm [20]. At the same time, some patients are reluctant to undergo surgery because of the permanent scar remaining in the neck. With the development of surgical minimally invasive technology, thyroid laparoscopic surgery without scar was used in clinical. However, its negative impact on the surrounding tissue cannot be ignored and may result in greater peripheral damage [21-23]. In addition, this treatment method is not suitable for all nodules and its use also depends on the location and nature of thyroid nodules. For patients with normal thyroid function, L-thyroxine inhibitory therapy is another way to treat thyroid nodules, but its effectiveness remains controversial. Meanwhile, L-thyroxine inhibitory therapy may also have side effects of atrial fibrillation and bone density reduction [24, 25].

In recent years, radiofrequency ablation technology has been widely used in minimally invasive of thyroid nodules due to its multiple advantages, such as minimally invasive, simple operation, controllability of the ablation range, stable and reliable[3, 4, 20]. Numerous studies have shown that radiofrequency ablation is a safe and reliable treatment for benign thyroid nodules and recurrent thyroid cancer $[3,4,20]$. However, it still has a certain incidence of complications because of the complex adjacent structure, such as recurrent laryngeal nerve $[5,9]$. The recurrent laryngeal nerve is easily damaged when the distance between the nodule edge and the recurrent laryngeal nerve was less than $2 \mathrm{~mm}$, and the nodules appearing in this area are called high-risk nodules [26, 27]. Deandred M [28] used the "incomplete ablation method" to avoid recurrent laryngeal nerve injury and it could effectively prevent recurrent laryngeal nerve injury. But a small amount of non-ablated tumor tissue adjacent to the recurrent laryngeal nerve was residual by this method and residual tumor tissue increased the risk of recurrence [29].

Due to the small size, and complex adjacent structures of the thyroid gland, the radiofrequency ablation power and the length of the electrode should be considered carefully to avoid the damage of the surrounding tissues. In this study, the power of $20 \mathrm{~W}$ and electrode with $0.5 \mathrm{~cm}$ active tip were selected for patients with nodule less than $1 \mathrm{~cm}$, while the power of $40 \mathrm{~W}$ and electrode with $1 \mathrm{~cm}$ active tip were selected for patients with nodule large than $1 \mathrm{~cm}$. During the ablation, the active tip was inside in the nodule and the power was relatively low. This could avoid the damage to the surrounding tissues as much as possible.

Hydrodissection technique is a very effective and safe pre-treatment method, and it was focused on separating the thyroid nodules from the surrounding important structures to make the nodules islanded. In order to avoid the occurrence of hemorrhage during hydrodissection, the selection of the gap and the needle entry route was especially important. The liquid was injected into the naturally existed gap between the cervical anatomical structures. The innovation of this research is that risk assessment based on zoning was established for the first time to clarify the risk degree of each nodule and whether it is necessary for nodules to use hydrodissection technique for pre-treatment. The results in this research confirmed that this novel method had better effect on the treatment of thyroid nodules. It improved the safety of nodular treatment though radiofrequency ablation technology and reduced the incidence of complications.

However, there were still some limitaions existed. This was a retrospective study, the result still needed to be confirmed further. Additionally, the performance of the hydrodissection technique had certain technical difficuty requiring the cooperation of the operator and the assistant. Thirdly, due to the small sample of the study, the result still needed to be further confirmed.

In summary, it is a very safe and effective way to carry out radiofrequency ablation after targeted preconditioning of thyroid nodules by hydrodissection technique according to risk assessment based on zoning and risk grading of nodules. Complete ablation can be achieved and no postoperative complication was occurred. In addition, this method is easily accepted and approved by patients. It will provide clinicians with greater help in the ablation treatment of thyroid nodules.

\section{Abbreviations}

RFA: Radiofrequency ablation; CA: complete ablation; VRR: volume reduction ratio.

\section{Acknowledgments}

This study was funded by the Project from Shanghai Science and Technology Committee (No. 16441901100) and Shanghai Municipal Planning Commission of science and Research Fund (No.20174Y0197). 


\section{Ethical approval}

All procedures performed in studies involving human participants were in accordance with the ethical standards of the institutional and/or national research committee and with the 1964 Helsinki declaration and its later amendments or comparable ethical standards.

\section{Informed consent}

Informed consent was obtained from all individual participants included in the study.

\section{Competing Interests}

The authors have declared that no competing interest exists.

\section{References}

1. Wong $\mathrm{KP}$, Lang $\mathrm{BH}$. Use of radiofrequency ablation in benign thyroid nodules: a literature review and updates. International Journal of Endocrinology,2013,(2013-11-3). 2013; 2013: 428363.

2. Ji HS, Baek JH, Ha EJ, Lee JH. Radiofrequency Ablation of Thyroid Nodules: Basic Principles and Clinical Application. International Journal of Endocrinology. 2012; 2012: 919650-.

3. Park HS, Baek JH, Park AW, Chung SR, Choi YJ, Lee JH. Thyroid Radiofrequency Ablation: Updates on Innovative Devices and Techniques. Korean J Radiol. 2017; 18: 615-23.

4. Cesareo R, Palermo A, Pasqualini V, Simeoni C, Casini A, Pelle G, et al. Efficacy and safety of a single radiofrequency ablation of solid benign non-functioning thyroid nodules. Arch Endocrinol Metab. 2017; 61: 173-9.

5. Baek JH, Lee JH, Sung JY, Bae JI, Kim KT, Sim J, et al. Complications encountered in the treatment of benign thyroid nodules with US-guided radiofrequency ablation: a multicenter study. Radiology. 2012; 262: 335-42.

6. Ha EJ, Baek JH, Lee JH. The efficacy and complications of radiofrequency ablation of thyroid nodules. Current Opinion in Endocrinology Diabetes \& Obesity. 2011; 18: 310-4.

7. Ha EJ, Baek JH, Lee JH, Kim JK, Shong YK. Clinical significance of vagus nerve variation in radiofrequency ablation of thyroid nodules. European Radiology. 2011; $21: 2151$

8. Gervasio A, Mujahed I, Biasio A, Alessi S. Ultrasound anatomy of the neck: The infrahyoid region. Journal of Ultrasound. 2010; 13: 85-9.

9. Wang JF, Wu T, Hu KP, Xu W, Zheng BW, Tong G, et al. Complications Following Radiofrequency Ablation of Benign Thyroid Nodules: A Systematic Review. Chin Med J (Engl). 2017; 130: 1361-70.

10. Yue, Wenwen, Wang, Bin, Shurong, $\mathrm{Xu}$, et al. Ultrasound guided percutaneous microwave ablation of benign thyroid;nodules: Safety and imaging follow-up in 222 patients. European Journal of Radiology. 2013; 82: e11.

11. Kubota S, Ohye H, Nishihara E, Kudo T, Ito M, Fukata S, et al. Effect of high dose methylprednisolone pulse therapy followed by oral prednisolone administration on the production of anti-TSH receptor antibodies and clinical outcome in Graves' disease. Endocr J. 2005; 52: 735-41.

12. Farkas EA, King TA, Bolton JS, Fuhrman GM. A comparison of total thyroidectomy and lobectomy in the treatment of dominant thyroid nodules. American Surgeon. 2002; 68: 682-3.

13. Wormald R, Sheahan P, Rowley S, Rizkalla H, Toner M, Timon C. Hemithyroidectomy for benign thyroid disease: who needs follow-up for hypothyroidism? Clinical Otolaryngology. 2008; 33: 587.

14. Mchenry CR, Slusarczyk SJ. Hypothyroidisim following hemithyroidectomy: incidence, risk factors, and management. Surgery. 2000; 128: 994-8.

15. Bron LP, O'Brien CJ. Total thyroidectomy for clinically benign disease of the thyroid gland. British Journal of Surgery. 2004; 91: 569-74.

16. Pelizzo MR, Merante Boschin I, Toniato A, Sorgato N, Marzola MC, Rubello D. Surgical therapeutic planning options in nodular goiter. Minerva Endocrinol. 2010; 35: 173-85.

17. Lynch J, Parameswaran R. Management of unilateral recurrent laryngeal nerve injury after thyroid surgery: A review. Head Neck. 2017; 39: 1470-8.

18. Hayward NJ, Grodski S, Yeung M, Johnson WR, Serpell J. Recurrent laryngeal nerve injury in thyroid surgery: a review. ANZ J Surg. 2013; 83: 15-21.

19. Sun GH, Peress L, Pynnonen MA. Systematic review and meta-analysis of robotic vs conventional thyroidectomy approaches for thyroid disease. Otolaryngol Head Neck Surg. 2014; 150: 520-32.

20. Che Y, Jin S, Shi C, Wang L, Zhang X, Li Y, et al. Treatment of Benign Thyroid Nodules: Comparison of Surgery with Radiofrequency Ablation. AJNR Am J Neuroradiol. 2015; 36: 1321-5.
21. Udomsawaengsup S, Navicharern P, Tharavej C, Pungpapong SU. Endoscopic transaxillary thyroid lobectomy: flexible vs rigid laparoscope. Journal of the Medical Association of Thailand = Chotmaihet thangphaet. 2004; 87 Suppl 2: S10.

22. Materazzi G, Fregoli L, Manzini G, Baggiani A, Miccoli M, Miccoli P. Cosmetic result and overall satisfaction after minimally invasive video-assisted thyroidectomy (MIVAT) versus robot-assisted transaxillary thyroidectomy (RATT): a prospective randomized study. World Journal of Surgery. 2014; 38: 1282-8.

23. Karakas E, Steinfeldt T, Gockel A, Schlosshauer T, Dietz C, Jäger J, et al. Transoral thyroid and parathyroid surgery--development of a new transoral technique. Surgery. 2011; 150: 108-15.

24. Hegedüs L, Bonnema SJ, Bennedbaek FN. Management of simple nodular goiter: current status and future perspectives. Endocrine Reviews. 2003; 24: 102.

25. Schneider R, Schneider M, Reiners C, Schneider P. Effects of levothyroxine on bone mineral density, muscle force, and bone turnover markers: a cohort study. Journal of Clinical Endocrinology \& Metabolism. 2012; 97: 3926-34.

26. Ha EJ, Baek JH, Lee JH, Kim JK, Shong YK. Clinical significance of vagus nerve variation in radiofrequency ablation of thyroid nodules. European Radiology. 2011; 21: 2151-7.

27. Ha EJ, Baek JH, Lee JH. Ultrasonography-Based Thyroidal and Perithyroidal Anatomy and Its Clinical Significance. Korean J Radiol. 2015; 16: 749-66.

28. Deandrea M, Sung JY, Limone P, Mormile A, Garino F, Ragazzoni F, et al. Efficacy and Safety of Radiofrequency Ablation Versus Observation for Nonfunctioning Benign Thyroid Nodules: A Randomized Controlled International Collaborative Trial. Thyroid. 2015; 25: 890-6.

29. Lim HK, Lee JH, Ha EJ, Sung JY, Kim JK, Baek JH. Radiofrequency ablation of benign non-functioning thyroid nodules: 4-year follow-up results for 111 patients. Eur Radiol. 2013; 23: 1044-9. 